\title{
Economics
}

HEI Working Paper No: 08/2004

\section{Modelling Environmental Risk}

\author{
Suhejla Hoti \\ School of Economics and Commerce \\ University of Western Australia \\ Michael McAleer \\ School of Economics and Commerce \\ University of Western Australia \\ Laurent L. Pauwels \\ Graduate Institute of International Studies
}

\begin{abstract}
As environmental issues have become increasingly important in economic research and policy for sustainable development, firms in the private sector have introduced environmental and social issues in conducting their business activities. Such behaviour is tracked by the Dow Jones Sustainable Indexes (DJSI) through financial market indexes that are derived from the Dow Jones Global Indexes. The sustainability activities of firms are assessed using criteria in three areas, namely economic, environmental and social. Risk (or uncertainty) is analysed empirically through the use of conditional volatility models of investment in sustainability-driven firms that are selected through the DJSI. The empirical analysis is based on financial econometric models to determine the underlying conditional volatility, with the estimates showing that there is strong evidence of volatility clustering, short and long run persistence of shocks to the index returns, and asymmetric leverage between positive and negative shocks to returns.
\end{abstract}

(C) The Authors.

All rights reserved. No part of this paper may be reproduced without the permission of the authors. 


\title{
Modelling Environmental Risk
}

\author{
Suhejla Hoti \\ School of Economics and Commerce \\ University of Western Australia \\ Michael McAleer \\ School of Economics and Commerce \\ University of Western Australia \\ Laurent L. Pauwels \\ Economics Section \\ Graduate Institute of International Studies, Geneva
}

Revised: August 2004

\begin{abstract}
As environmental issues have become increasingly important in economic research and policy for sustainable development, firms in the private sector have introduced environmental and social issues in conducting their business activities. Such behaviour is tracked by the Dow Jones Sustainable Indexes (DJSI) through financial market indexes that are derived from the Dow Jones Global Indexes. The sustainability activities of firms are assessed using criteria in three areas, namely economic, environmental and social. Risk (or uncertainty) is analysed empirically through the use of conditional volatility models of investment in sustainability-driven firms that are selected through the DJSI. The empirical analysis is based on financial econometric models to determine the underlying conditional volatility, with the estimates showing that there is strong evidence of volatility clustering, short and long run persistence of shocks to the index returns, and asymmetric leverage between positive and negative shocks to returns.
\end{abstract}

Keywords: Environmental sustainability index, environmental risk, conditional volatility, Dow Jones Sustainability Indexes, GARCH, GJR, persistence, shocks, asymmetry, moment condition, log-moment condition. 


\section{Introduction}

Environmental sustainability is not limited to the domain of policy making and implementation, but also involves the economic and financial behaviour of agents and firms in the private sector. Investors increasingly perceive sustainable economic behaviour by firms as an improved and disciplined management strategy, pushing investors to diversify their financial portfolios and to invest in "sustainable" companies.

The Dow Jones Sustainability Indexes (DJSI) are part of a family of financial indexes that are derived in the same manner as the more well-known financial market indexes, such as the Dow Jones Industrial Average (DJIA) and the STOXX index. The DJSI is based on a selection of leading firms that take environmental and social issues seriously in their business practices.

In this paper, we analyse empirically the conditional volatility (alternatively, conditional variance, risk or uncertainty) associated with investing in leading sustainability-driven firms. Important issues to be examined include a consideration of the volatility inherent in the returns to the sustainability indexes, and differences in the returns and volatility behaviour of these indexes in comparison with financial indexes. As the concept of environmental risk has had several different interpretations in the economics literature, we will use the following definition:

Environmental risk is the volatility associated with the returns to a variety of environmental sustainability indexes.

The techniques used in this paper have been used primarily in the field of financial econometrics, and these will provide insight into the volatility in the underlying environmental sustainability indexes. To date there does not seem to have been any empirical analysis of such sustainability indexes. Indeed, based on a search of the ECONLIT database, Jha and Murthy (2003) have argued that economists have shown very little interest in sustainability indexes to date. Marinova and McAleer (2003) applied similar financial econometric techniques to analyse the volatility inherent in ecological patents. Although Marinova and McAleer (2004) do not consider 
modelling risk associated with anti-pollution technology strengths indicators, the techniques used in this paper could also be used for such an analysis.

The plan of the paper is as follows. Section 2 presents the Dow Jones Sustanability Indexes and discusses the key features of the various indexes. Univariate conditional volatility models for daily observations on the sustainability indexes are presented in Section 3. The data are described

in Section 4, and the empirical results for the univariate models are analysed in Section 5. Some concluding remarks are given in Section 6.

\section{Dow Jones Sustainability Indexes (DJSI)}

In financial markets, some firms have paid serious attention to incorporate environmental and social issues within their business planning strategies. The Dow Jones Sustainability Indexes (DJSI) were started in 1999, and report on the financial performance of leading sustainabilitydriven firms worldwide (this information is available at http://www.sustainability-indexes.com). These sustainability indexes were created by the Dow Jones Indexes, STOXX Limited and the SAM group.

The main purpose of the DJSI is to provide asset managers with a benchmark to manage sustainability portfolios and develop financial products and services that are linked to sustainable economic, environmental and social criteria. Sustainable development and social issues are frequently promoted in the public sector, and are implemented through government policy, international organisations or non-governmental actions. The DJSI, however, quantify the development and promotion of sustainable values on the environment and society by the business community. These indexes enable the promotion of sustainability within the private sector by informing investors about firms that behave in an environmentally sustainable manner.

As for the Dow Jones Global Indexes, the DJSI features the same methods for calculating, reviewing and publishing data. The DJSI is used in 14 countries, with 50 licenses having been sold to asset managers. There are two sets of DJSI indexes, namely the DJSI World and the DJSI STOXX (which is a pan-European index). The latter index is also subdivided into another regional index, namely DJSI EURO STOXX, which accounts solely for Euro-zone countries. 


\subsection{DJSI World and DJSI STOXX}

Dow Jones Sustainability World Indexes (DJSI World) is constructed by selecting the leading $10 \%$ of sustainability firms (which number more than 300 ) in the Dow Jones Global Index, which covers 59 industries over 34 countries. The composite DJSI World is available in four specialised subset indexes, which exclude companies that generate revenue from (1) tobacco, (2) gambling, (3) armaments or firearms, and (4) alcohol in addition to the three previously mentioned items.

Two regional indexes, the DJSI STOXX and DJSI EURO STOXX, were first published on 15 October 2001. They include 179 components and record the financial performance of the leading $20 \%$ of European sustainability companies chosen from the Dow Jones STOXX 600. Moreover, two specialised indexes are made available for both regional composite indexes, which corresponds to category (4) given above.

The DJSI World and DJSI STOXX are reviewed annually and quarterly to ensure consistency. They also accommodate potential changes in the behaviour and status of companies which could affect their sustainability performance (such as bankruptcies, mergers and takeovers). Both indexes comprise companies from 60 industry groups and 18 market sectors.

\subsection{Corporate Sustainability: Reviewing Process and Criteria}

The Corporate Sustainability Assessment is a methodology which assesses the relative risks and opportunities for eligible companies according to specific sustainability criteria. There are general and industry-specific criteria, with the latter accounting for $60 \%$ and $40 \%$ of the assessment for the DJSI STOXX and World, respectively, in the economic, environment and social dimensions. Table 1 highlights the individual factors and weights that are used in the general criteria to construct the Corporate Sustainability Performance Score. This scheme enables a determination of the overall sustainability score and assessment of the eligibility of firms to enter the DJSI. More specific information is available at http://www.sustainability-indexes.com. 
Sources of information for such assessments come from online questionnaires, company documentation, publicly available information, policies, reports and direct contacts with a variety of firms. The information provided is verified, and their quality and objectivity are assured through an external audit of the assessing teams. Moreover, when a company has been selected to join the DJSI World or DJSI STOXX, its sustainability performance is monitored on the basis of all the criteria for which it was selected.

\section{Univariate Models of Conditional Volatility for Sustainability Indexes}

This section discusses the specification and properties of the conditional volatility models to be used to estimate the volatility in the daily Dow Jones Sustainability Indexes. The specifications to be estimated are based on Engle's (1982) autoregressive conditional heteroskedasticity (ARCH) model and its various extensions. Specifically, this paper uses Bollerslev's (1986) symmetric generalised ARCH (GARCH) model, and the asymmetric GJR model of Glosten, Jagannathan and Runkle (1992), which distinguishes between the impact of negative and positive shocks on leverage through changes in the debt-equity ratio. These two models considered are the most widely-used in the financial volatility literature. The significance of the parameter estimates is equivalent to reporting diagnostics regarding the presence of conditional volatility (or risk).

Consider the stationary $\mathrm{AR}(1)-\mathrm{GARCH}(1,1)$ model of $y_{t}$, the return on a stock index or on a financial asset (as measured in log-differences):

$$
y_{t}=\rho_{1}+\rho_{2} y_{t-1}+\varepsilon_{t},\left|\rho_{2}\right|<1
$$

where the shocks to returns, $\varepsilon_{t}$, are given by:

$$
\begin{aligned}
& \varepsilon_{t}=\eta_{t} \sqrt{h_{t}}, \quad \eta_{t} \sim \operatorname{iid}(0,1) \\
& h_{t}=\omega+\alpha \varepsilon_{t-1}^{2}+\beta h_{t-1},
\end{aligned}
$$


in which $\omega>0, \alpha \geq 0, \beta \geq 0$ are sufficient conditions to ensure a strictly positive conditional variance, $h_{t}>0$. The ARCH (or $\alpha$ ) effect captures the short run persistence of shocks, and the GARCH (or $\beta$ ) effect indicates the contribution of shocks to long run persistence $(\alpha+\beta)$. In GARCH models, the parameters are typically estimated by the maximum likelihood method (MLE) to Quasi-Maximum Likelihood Estimators (QMLE) in the absence of normality of the standardized residuals, $\eta_{t}$. For further details, see Li, Ling and McAleer (2002).

In the financial econometrics literature, there are several important theoretical results that are relevant for the GARCH model. Ling and McAleer (2002a) established the necessary and sufficient conditions for strict stationarity and ergodicity, as well as for the existence of all moments, for the univariate $\operatorname{GARCH}(p, q)$ model, and Ling and McAleer (2003) demonstrated that the QMLE for $\operatorname{GARCH}(p, q)$ is consistent if the second moment is finite, $E\left(\varepsilon_{t}^{2}\right)<\infty$, and asymptotically normal if the fourth moment is finite, $E\left(\varepsilon_{t}^{4}\right)<\infty$. The necessary and sufficient condition for the existence of the second moment of $\varepsilon_{t}$ for the $\operatorname{GARCH}(1,1)$ model is $\alpha+\beta<1$, which is straightforward to check in practice.

Another important result is that the log-moment condition for the QMLE of GARCH(1,1), which is a weak sufficient condition for the QMLE to be consistent and asymptotically normal, is given by $E\left(\log \left(\alpha \eta_{t}^{2}+\beta\right)\right)<0$. These results were derived in Elie and Jeantheau (1995) and Jeantheau (1998) for consistency and Boussama (2000) for asymptotic normality. In practice, it is more straightforward to verify the second moment condition than the weaker log-moment condition, as the latter is a function of unknown parameters and the mean of a random variable.

The GARCH model proposes a symmetric treatment of the effects of shocks on the conditional variance, $h_{t}$, such that positive and negative shocks affect the conditional volatility in an identical manner. For this reason, the GJR $(1,1)$ model accommodates the asymmetric effects of shocks, whereby negative shocks are presumed to have a greater impact on volatility (hence, greater leverage) than positive shocks of a similar magnitude. The asymmetric GJR $(1,1)$ model is given as follows: 


$$
h_{t}=\omega+\left(\alpha+\gamma I\left(\eta_{t-1}\right)\right) \varepsilon_{t-1}^{2}+\beta h_{t-1},
$$

where $\omega>0, \alpha \geq 0, \alpha+\gamma \geq 0, \beta \geq 0$ are sufficient conditions for $h_{t}>0$, and $I\left(\eta_{t}\right)$ is an indicator variable defined by:

$$
I\left(\eta_{t}\right)= \begin{cases}1, & \varepsilon_{t}<0 \\ 0, & \varepsilon_{t} \geq 0\end{cases}
$$

as $\eta_{t}$ has the same sign as $\varepsilon_{t}$. The role of the indicator variable is to distinguish between positive and negative shocks, where the asymmetric effect $(\gamma>0)$ measures the contribution of shocks to both short run persistence $(\alpha+\gamma / 2)$ and long run persistence $(\alpha+\beta+\gamma / 2)$.

As in the case of the GARCH model, some important theoretical developments are available for the GJR model. In the case of symmetry of $\eta_{t}$, the regularity condition for the existence of the second moment of $\operatorname{GJR}(1,1)$ is $\alpha+\beta+\gamma / 2<1$ (see Ling and McAleer (2002b)). Moreover, the weak $\log$-moment condition for $\operatorname{GJR}(1,1), E\left(\ln \left[\left(\alpha+\gamma I\left(\eta_{t}\right)\right) \eta_{t}^{2}+\beta\right]\right)<0$, is sufficient for the consistency and asymptotic normality of the QMLE (see McAleer et al. (2002)).

\section{Data Description}

The DJSI World, DJSI STOXX, and DJSI EURO STOXX are available at no charge from the Dow Jones Sustainability Indexes website (the information is available at http://www.sustainability-indexes.com). All the indexes are calculated as both the returns on individual prices and returns on the index, in both USD and EURO currencies. The only specialised indexes that are freely available for the DJSI are those that exclude all four components, as described in section 2.1 above.

The indexes are available on both a daily and monthly basis. In this paper, we estimate models using only the daily data as they are more informative. Daily data are available from 31/12/93 to 
31/03/2004 for DJSI World, and from 31/12/98 to 31/03/2004 for both DJSI STOXX and DJSI EURO STOXX. Monthly data are from January 1994 for DJSI World and from January 1999 for DJSI STOXX, both until March 2004. Data for DJSI EURO STOXX are not available on a monthly basis. As the method of aggregation is not publicly available, we are unable to construct the monthly data for this series.

All dividend payments are included in the price and index returns. Only dividends from nonoperating income or cash dividends greater than $10 \%$ of the share price are included in the price indexes, which are based on the Laspeyres formula. The base date is 31/12/1998 and the corresponding base value is 1,000 for DJSI World and 100 for DJSI STOXX. Calculation of the indexes is based on real time stock prices and currency rates, the number of shares outstanding for each stock class, and corporate action information as input data. Specific information on stock prices and the manner in which the financial information has been incorporated are available from the guide to these indexes (DJSI, 2003a, 2003b).

The empirical analysis in this paper involves the three indexes and the three specialised counterparts for the period 31/12/1998 to 31/03/2004. The Dow Jones Indexes are calculated on a 7-days per week basis, whereas the STOXX indexes are calculated on a 5-days per week basis. We use the total returns indexes denominated in USD for the empirical analysis rather than the price returns.

Table 2 reports the correlation coefficients for the six DJSI indexes and two prominent financial indexes, namely the Dow Jones Industrial Average (DJIA) and Standard \& Poor's 500 (SP500). Using data for the period January 1999 to March 2004, pairwise correlation coefficients are calculated for the eight indexes, as well as their percentage changes (as expressed in logdifferences). For the regional DJSI STOXX, the monthly values are calculated from the daily values, and start from 31/12/1998.

In levels, the SP500 is more highly correlated with the DJSI than is the DJSI with the DJIA. This pattern is not repeated in log-differences (or returns). Not surprisingly, the correlations are typically much higher in levels than in log-differences. The three highest correlations in both levels and log-differences are DJSI World, DJSI STOXX and DJSI EURO with their XA 
counterparts, namely those that exclude tobacco, gambling, armaments or firearms, and alcohol. Finally, all the DJSI are highly correlated with their corresponding specialised indexes in both levels and log-differences. An implication of this result is that it does not seem to make any financial difference whether an investment occurs in the sustainability index or in its specialised counterpart, except for possible ethical reasons.

The levels and returns for each of the five principal indexes, namely DJSI World, DJSI STOXX, DJSI EURO, DJIA and S\&P500, are presented in Figure 1. Apart form DJIA, the patterns in both series are remarkably similar, as would be expected from the simple correlations in Table 2 . There is a substantial clustering of returns for each series, with only the DJIA returns apparently being different from the remaining four series.

\section{Empirical Results}

As shown in Figure 2, there is substantial volatility in each of the five series. Using the data on the daily indexes, the conditional mean is modelled in each case as an AR(1) process, as in equation (1). Table 3 provides the ADF and PP unit root tests for the sustainability indexes as well as their log-differences (or rates of return). It is clear that the sustainability indexes are nonstationary, while their rates of return are stationary.

The univariate $\mathrm{AR}(1)-\mathrm{GARCH}(1,1)$ and $\mathrm{AR}(1)-\mathrm{GJR}(1,1)$ models are used to provide estimates of the conditional volatilities associated with the five indexes for the period 31/12/1998 to 31/03/2004. The Berndt, Hall, Hall and Hausman (BHHH) (1974) algorithm in the econometric software package EViews 4.1 is used to maximize the conditional log-likelihood function. RATS 6 gave virtually identical results. Tables 4-5 report two sets of t-ratios associated with each parameter estimate, namely the asymptotic t-ratios and the Bollerslev and Wooldridge (1992) robust t-ratios.

The GARCH(1,1) estimates in Table 4 show that the ARCH (or $\alpha$ ) estimates are always positive and significant, as expected, and the GARCH (or $\beta$ ) estimates are quite close to unity and highly significant, which is a standard result for financial time series returns. Thus, both the short run 
and long run persistence of shocks are highly significant. The log-moment and second moment conditions are satisfied in all five cases, which indicate that the QMLE are consistent and asymptotically normal. These are very strong and robust results.

In Table 5, the GJR $(1,1)$ estimates suggest that the ARCH (or $\alpha$ ) estimates are always insignificant, which might be regarded as being contrary to expectations, while the GARCH (or $\beta$ ) estimates are again quite high, but not as close to unity as in the case of $\operatorname{GARCH}(1,1)$. The asymmetry parameter, $\gamma$, is always positive and significant, which suggests that negative shocks have a greater impact in increasing volatility than positive shocks have in decreasing volatility. Thus, the leverage of negative shocks exceeds that of positive shocks. Moreover, both the short run persistence, which arises predominantly from negative shocks, and the long run persistence of shocks are highly significant. Finally, while the log-moment moment could not be calculated for any of the five series, the second moment condition was satisfied in each case. Therefore, the QMLE are consistent and asymptotically normal in all cases, which provides another strong and robust set of results. The trade-off between GARCH and GJR is problematic in all five cases as the ARCH effects are insignificant for GJR but the estimated asymmetry parameters are always significant.

The strong empirical evidence of the existence of conditional volatility in all five series is given in Figure 2, together with the sample volatility, which is defined as the squared deviation from the mean of the respective series. It is clear that there is strong evidence of volatility clustering, with an absence of outliers and extreme observations, which can be pervasive in financial time series returns. Overall, S\&P500 seems to be more closely related to the DJSI indexes than is DJIA to the DJSI.

\section{Conclusion}

Increasingly important environmental issues for sustainable development have led to firms in the private sector examining environmental and social issues. Such behaviour is tracked by the Dow Jones Sustainable Indexes (DJSI) through financial market indexes that are derived from the Dow Jones Global Indexes. The sustainability activities of firms are assessed using criteria in three 
areas, namely economic, environmental and social. Risk (or uncertainty) is analysed empirically through the use of conditional volatility models of investment in sustainability-driven firms that are selected through the DJSI.

In this paper, we analysed empirically the risks (or uncertainty) associated with investing in leading sustainability-driven firms. Important issues included a consideration of the volatility inherent in sustainability indexes, and differences in the returns and volatility behaviour of these indexes in comparison with financial indexes. The techniques used in this paper were derived from the field of financial econometrics, which were used to gain insights into the volatility in the underlying sustainability indexes.

The empirical estimates showed that there was strong evidence of volatility clustering, with both short and long run persistence of shocks to the index returns. Overall, both the $\operatorname{GARCH}(1,1)$ and GJR $(1,1)$ models were empirically supported. However, the trade-off between GARCH and GJR was problematic in all cases as the ARCH effects were insignificant for GJR but the estimated asymmetry parameters were always significant.

\section{Acknowledgements}

The authors would like to thank six referees for their helpful comments and suggestions, and Kathrin Füllemann of SAM Indexes GmbH for helpful information. The first and second authors wish to acknowledge the financial support of the Australian Research Council. An earlier version of the paper was presented at the Biennial Meeting of the International Environmental and Software Society, Osnabrück, Germany, July 2004. 


\section{References}

Berndt, E.K., B.H. Hall, R.E. Hall and J.A. Hausman (1974), Estimation and inference in nonlinear structural models, Annals of Economic and Social Measurement, 3, 653-665.

Bollerslev, T. (1986), Generalized Autoregressive Conditional Heteroskedasticity, Journal of Econometrics, 31, 307-327.

Bollerslev, T. and J.M. Wooldridge (1992), Quasi-maximum likelihood estimation and inference in dynamic models with time-varying covariances, Econometric Reviews, 11, 143-173.

Boussama, F. (2000), Asymptotic Normality for the Quasi-maximum Likelihood Estimator of a GARCH Model, Comptes Rendus de l'Académie des Sciences, Série I, 331, 81-84 (in French).

Chan, F., S. Hoti and M. McAleer (2002), Structure and Asymptotic Theory for Multivariate Asymmetric Volatility: Empirical Evidence for Country Risk Ratings, paper presented to the 2002 Australasian Meeting of the Econometric Society, Brisbane, Australia, July 2002.

Dow Jones Sustainability Indexes (2003a), Dow Jones Sustainability World Indexes Guide, available at http://www.sustainability-indexes.com, Version 5.0, September.

Dow Jones Sustainability Indexes (2003b), Dow Jones STOXX Sustainability Indexes Guide, available at http://www.sustainability-indexes.com, Version 3.0, September.

Elie, L. and T. Jeantheau (1995), Consistency in Heteroskedastic Models, Comptes Rendus de l'Académie des Sciences, Série I, 320, 1255-1258. (in French)

Engle, R.F. (1982), Autoregressive Conditional Heteroscedasticity with Estimates of the Variance of United Kingdom Inflation, Econometrica, 50, 987-1007.

Glosten, L., R. Jagannathan and D. Runkle (1992), On the Relation Between the Expected Value and Volatility of Nominal Excess Returns on Stocks, Journal of Finance, 46, 1779-1801.

Hoti, S. and M. McAleer (2004), An Empirical Assessment of Country Risk Ratings and Associated Models, to appear in Journal of Economic Surveys (September issue).

Jeantheau, T. (1998), Strong Consistency of Estimators for Multivariate ARCH Models, Econometric Theory, 14, 70-86.

Jha. J. and K.V.B. Murthy (2003), A Critique of the Environmental Sustainability Index, unpublished paper, Economics, RSPAS, Australian National University.

Li, W.K., S. Ling and M. McAleer (2002), Recent Theoretical Results for Time Series Models with GARCH Errors, Journal of Economic Surveys, 16, 245-269. Reprinted in M. McAleer and L. Oxley (eds.), Contributions to Financial Econometrics: Theoretical and Practical Issues, Blackwell, Oxford, 2002, pp. 9-33. 
Ling, S. and M. McAleer (2002a), Necessary and Sufficient Moment Conditions for the GARCH(r,s) and Asymmetric Power GARCH(r,s) Models, Econometric Theory, 18, 722-729.

Ling, S. and M. McAleer (2002b), Stationarity and the Existence of Moments of a Family of GARCH Processes, Journal of Econometrics, 106, 109-117.

Ling, S. and M. McAleer (2003), Asymptotic Theory for a Vector ARMA-GARCH Model, Econometric Theory, 19, 278-308.

Marinova, D. and M. McAleer (2003), Modelling trends and volatility in ecological patents in the USA, Environmental Modelling and Software, 18(3), 195-203.

Marinova, D. and M. McAleer (2004), "Anti-pollution technology strengths indicators: international rankings", to appear in Environmental Modelling and Software.

McAleer, M., F. Chan and D. Marinova (2002), An Econometric Analysis of Asymmetric Volatility: Theory and Application to Patents, paper presented to the Australasian Meeting of the Econometric Society, Brisbane, July 2002, to appear in Journal of Econometrics. 
Table 1. Corporate Sustainability Assessment Criteria

\begin{tabular}{|c|c|c|c|c|c|}
\hline \multicolumn{2}{|c|}{ Economics } & \multicolumn{2}{|c|}{ Environment } & \multicolumn{2}{|c|}{ Social } \\
\hline Criteria & Weight (\%) & Criteria & Weight (\%) & Criteria & Weight (\%) \\
\hline $\begin{array}{l}\text { Codes of Conduct, } \\
\text { Corruption }\end{array}$ & 3 & $\begin{array}{l}\text { Environmental } \\
\text { Policy/Management }\end{array}$ & 3 & Philanthropy & 2.4 \\
\hline $\begin{array}{l}\text { Corporate } \\
\text { Governance }\end{array}$ & 5.4 & $\begin{array}{l}\text { Environmental } \\
\text { Performance }\end{array}$ & 4.2 & $\begin{array}{l}\text { Stakeholder } \\
\text { Engagement }\end{array}$ & 4.2 \\
\hline $\begin{array}{l}\text { Customer } \\
\text { Relationship } \\
\text { Management }\end{array}$ & 3 & $\begin{array}{l}\text { Environ. } \\
\text { Reporting }\end{array}$ & 1.8 & $\begin{array}{l}\text { Labour Practice } \\
\text { Indicator }\end{array}$ & 3 \\
\hline $\begin{array}{l}\text { Financial } \\
\text { Robustness }\end{array}$ & 3.6 & Industry Specific & Variable & $\begin{array}{l}\text { Human Capital } \\
\text { Development }\end{array}$ & 1.8 \\
\hline Investor Relations & 2.4 & & & $\begin{array}{l}\text { Knowledge } \\
\text { Management }\end{array}$ & 3 \\
\hline $\begin{array}{l}\text { Risk and Crisis } \\
\text { Management }\end{array}$ & 3.6 & & & $\begin{array}{l}\text { Social } \\
\text { Reporting }\end{array}$ & 1.8 \\
\hline $\begin{array}{l}\text { Measurement } \\
\text { System/Scorecards }\end{array}$ & 4.2 & & & $\begin{array}{l}\text { Talent } \\
\text { Attraction \& } \\
\text { Retention }\end{array}$ & 2.4 \\
\hline Strategic Planning & 5.4 & & & $\begin{array}{l}\text { Standard for } \\
\text { Suppliers }\end{array}$ & 1.8 \\
\hline Industry Specific & Variable & & & Industry Specific & Variable \\
\hline
\end{tabular}


Table 2. Correlation Coefficients for Eight Indexes

\section{Levels}

\begin{tabular}{|c|c|c|c|c|c|c|c|}
\hline Index & S\&P500 & DJSI-W & DJSIWXA & DJSI-STOXX & DJSI-STOXX-XA & DJSI-EURO & DJSI-EURO-XA \\
\hline DJIA & 0.8182 & 0.7726 & 0.7659 & 0.2659 & 0.2793 & 0.4599 & 0.4498 \\
\hline S\&P500 & & 0.9773 & 0.9772 & 0.4705 & 0.4888 & 0.7006 & 0.6963 \\
\hline DJSI-W & & & 0.9998 & 0.5086 & 0.52489 & 0.7100 & 0.7059 \\
\hline DJSI-W-XA & & & & 0.5135 & 0.52971 & 0.7140 & 0.7099 \\
\hline DJSI-STOXX & & & & & 0.9996 & 0.9328 & 0.9320 \\
\hline DJSI-STOXX-XA & & & & & & 0.9408 & 0.9403 \\
\hline DJSI-EURO & & & & & & & 0.9997 \\
\hline
\end{tabular}

Notes: W: World; XA: Excluding tobacco, gambling, armaments or firearms, and alcohol; EURO: Euro-Zone.

\section{Log-Differences}

\begin{tabular}{|c|c|c|c|c|c|c|c|}
\hline Index & S\&P500 & DJSI-W & DJSIWXA & JSI-STOXX & DJSI-STOXX-XA & DJSI-EURO & DJSI-EURO-XA \\
\hline DJIA & 0.9168 & 0.8551 & 0.8487 & 0.1071 & 0.1158 & 0.1862 & 0.1827 \\
\hline S\&P500 & & 0.9298 & 0.9235 & 0.0620 & 0.0725 & 0.1726 & 0.1691 \\
\hline DJSI-W & & & 0.9977 & 0.0835 & 0.0917 & 0.1794 & 0.1763 \\
\hline DJSI-W-XA & & & & 0.1003 & 0.1082 & 0.1960 & 0.1927 \\
\hline DJSI-STOXX & & & & & 0.9996 & 0.9367 & 0.9363 \\
\hline DJSI-STOXX-XA & & & & & & 0.9391 & 0.9389 \\
\hline DJSI-EURO & & & & & & & 0.9997 \\
\hline
\end{tabular}

Notes: W: World; XA: Excluding tobacco, gambling, armaments or firearms, and alcohol; EURO: Euro-Zone. 
Table 3: Unit Root Test Statistics for Daily Stock Indexes

\section{Logarithms}

\begin{tabular}{|l|c|c|}
\hline Indexes & ADF & Phillips-Perron \\
\hline DJSI World & -1.310 & -1.314 \\
DJSI STOXX & -1.427 & -1.512 \\
DJSI EURO STOXX & -1.240 & -1.318 \\
DJIA & -2.685 & -2.690 \\
S\&P500 & -1.852 & -1.906 \\
\hline
\end{tabular}

Note: The simulated critical value at $5 \%$ level of significance is -3.4156 .

\section{Log-Differences}

\begin{tabular}{|l|c|c|}
\hline Indexes & ADF & Phillips-Perron \\
\hline DJSI World & -19.566 & -39.111 \\
DJSI STOXX & -17.550 & -36.091 \\
DJSI EURO STOXX & -18.123 & -36.336 \\
DJIA & -17.502 & -37.812 \\
S\&P500 & -18.173 & -37.975 \\
\hline
\end{tabular}

Note: The simulated critical value at $1 \%$ level of significance is -2.5673 . 
Table 4. AR(1)-GARCH(1,1)

\begin{tabular}{|lccccc|}
\hline Index & $\omega$ & $\alpha$ & $\beta$ & Log-moment & Second moment \\
\hline DJSI World & 0 & 0.042 & 0.932 & -0.024 & 0.975 \\
& 4.742 & 8.378 & 116.153 & & \\
\hline DJSI STOXX & 2.207 & 3.284 & 47.010 & & 0.971 \\
& 0 & 0.096 & 0.874 & -0.039 & \\
\hline DJSI EURO STOXX & 3.144 & 6.389 & 43.034 & & 0.979 \\
& 2.984 & 4.423 & 35.034 & & \\
& 0 & 0.085 & 0.894 & -0.029 & 0.990 \\
DJIA & 2.791 & 6.589 & 54.460 & & \\
& 2.995 & 4.348 & 41.889 & & 0.976 \\
& 0 & 0.076 & 0.914 & -0.019 & \\
\hline S\&P 500 & 2.189 & 5.227 & 60.971 & & \\
& 2.357 & 4.623 & 51.479 & & \\
& 0 & 0.082 & 0.894 & -0.032 & \\
& 3.091 & 5.375 & 46.178 & & \\
& 2.653 & 4.464 & 39.091 & & \\
\end{tabular}

Note: The three entries corresponding to each parameter are their estimates, their asymptotic t-ratios, and the Bollerslev and Wooldridge (1992) robust t-ratios. 
Table 5. AR(1)-GJR(1,1)

\begin{tabular}{|lccccccc|}
\hline Index & $\omega$ & $\alpha$ & $\gamma$ & $\beta$ & $\alpha+\gamma / 2$ & $\begin{array}{c}\text { Log- } \\
\text { moment }\end{array}$ & $\begin{array}{c}\text { Second } \\
\text { moment }\end{array}$ \\
\hline DJSI World & 0 & 0.003 & 0.063 & 0.935 & 0.034 & NA & 0.969 \\
& 6.978 & 0.583 & 11.313 & 150.823 & & & \\
\hline DJSI STOXX & 2.226 & 0.204 & 2.848 & 42.570 & & & 0.971 \\
& 0 & -0.001 & 0.151 & 0.896 & 0.074 & NA & \\
& 4.423 & -0.085 & 5.745 & 57.433 & & & 0.976 \\
DJSI EURO STOXX & 3.318 & -0.049 & 4.543 & 40.197 & & & \\
& 0 & 0.013 & 0.123 & 0.901 & 0.075 & NA & \\
\hline DJIA & 4.057 & 1.193 & 5.257 & 61.213 & & & 0.985 \\
& 3.391 & 0.707 & 4.120 & 45.177 & & & \\
& 0 & -0.014 & 0.138 & 0.930 & 0.055 & NA & \\
\hline S\&P 500 & 2.546 & -1.468 & 6.377 & 62.830 & & & 0.988 \\
& 3.387 & -0.835 & 4.872 & 69.749 & & & \\
& 0 & -0.024 & 0.181 & 0.922 & 0.066 & NA & \\
\hline
\end{tabular}

Note: The three entries corresponding to each parameter are their estimates, their asymptotic t-ratios, and the Bollerslev and Wooldridge (1992) robust t-ratios. 
Figure 1. Daily Data for Sustainability Indexes (left) and Index Returns (right)

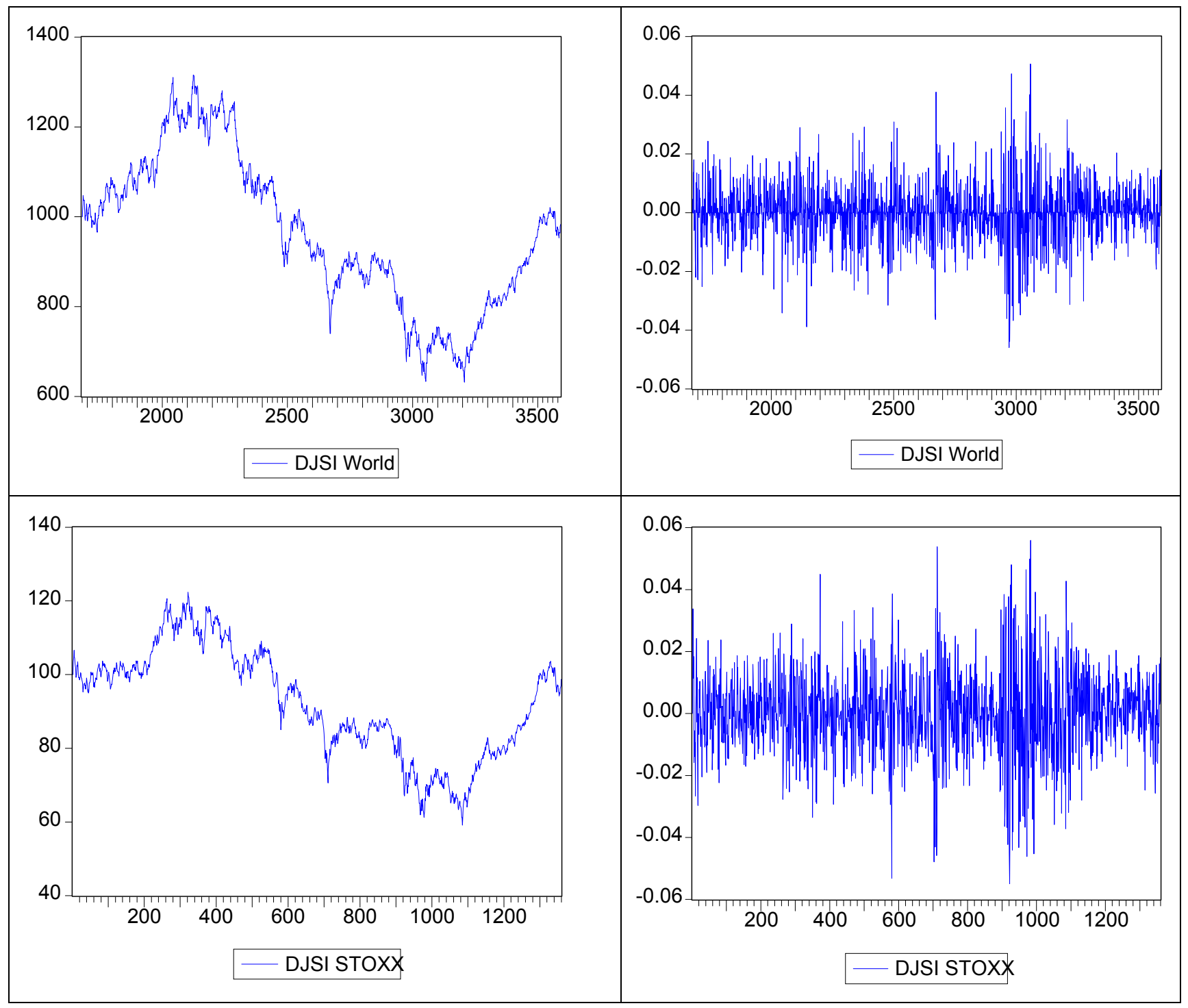




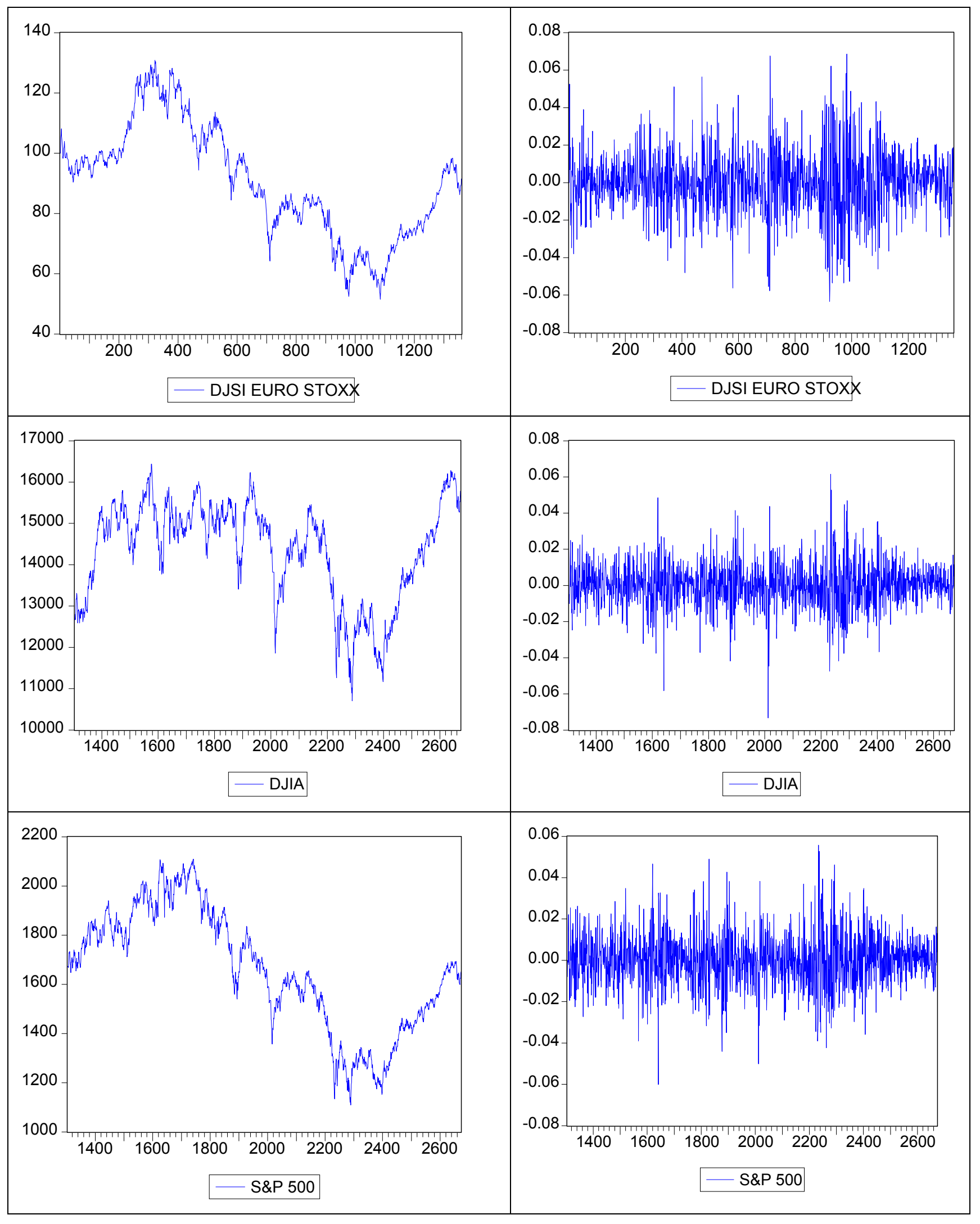


Figure 2. Sample Volatility (left) and Estimated GARCH(1,1) Volatility (right)

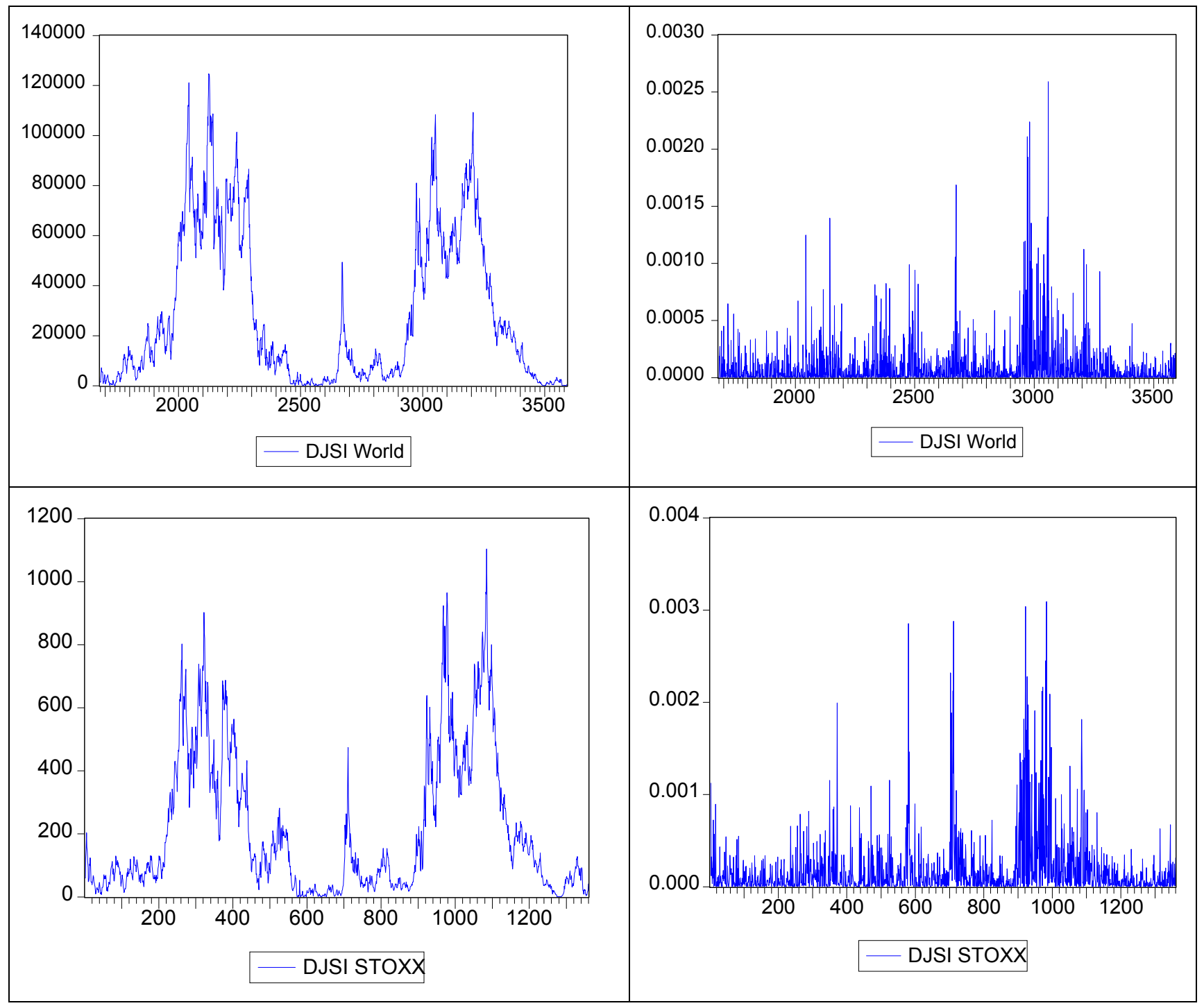




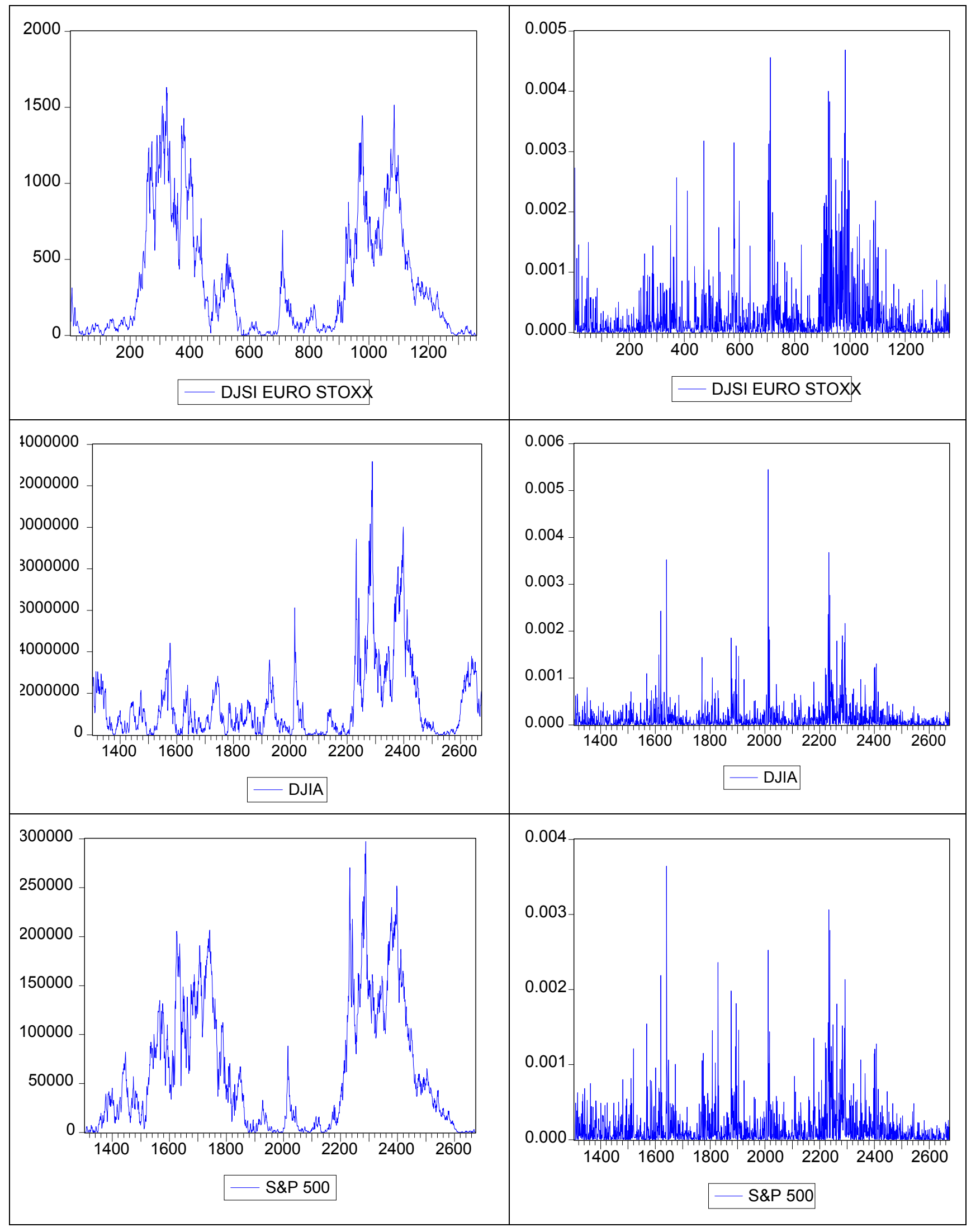

